\title{
LA INDEPENDĖNCIA DE LA TEORIA MORAL EN DESCARTES
}

\author{
Àngel Puyol \\ (Universitat Autònoma de Barcelona)
}

La meva comunicació pretén analitzar la metodologia implicita en la teoria moral de Descartes. A partir de l'existència d'una clara independència metodològica de la teoria moral respecte de la resta de la filosofia cartesiana - com ara descobrirem-, intento comprovar la similitud entre l'esquema metodològic de l'ètica cartesiana i la teoria moral contemporània.

Per Descartes, la primera tasca de la filosotia és l'apropiament d'un mètode capaç de proporcionar certesa sobre els descobriments filosòfics. En aquest sentit, diem que Descartes inicia la modernitat filosofica, atorgant a l'epistemologia una prinacia metodologica respecte de la resta de la filosofia. És a dir, ts proritari resoldre els problemes gnoseològics per posteriorment construir, a partir dels ciments de l'epistemologia, la resta de disciplines filosòliques.

Malgrat no poder reduir la filosofia de Descartes a metodologia, hom ha de recondixer que el mètode garanteix la unitat de la raó, de forma que l'absència de métode convertiria la filosofia en un conjunt de disciplines inconnexes, en una cantarella dissonant a l'harmoniós esperit racional. El mètode aporta certesa, tranquilitza l'esperit filosòfic i fins i tot identifica la mateixa racionalitat.

En el Discurs del mètode, el tilosof francès exposa les condicions metodològiques de la filosofia. En primer Iloc - declara Descartes - liaig d'esforçar-me en "no admetre res com a veritable que no sabès de manera evident que ho era, is a dir, evitar curosament la precipitació i la prevenció, i no comprendre en els meus judicis sinó allò que es presentés al meu esperit tan clarament i tan distintament que no tingués ocasió de posar-ho en dubte"; en segon lloc, haig de "dividir cadascuna de les dificultats que examines en tantes parts com fos possible i que es requerissin per tal de resoldre-les miltor"; en tercer lloc, "conduir amb ordre els meus pensaments, comerçant pels objectes més simples i facils de conėixer per tal d'enlairar-me a poc a poc, com gradualment, tins al coneixement dels mes compostos, i, fins $\mathbf{j}$ tot, suposant ordre entre aquells que no es precedeixen els uns als altres de mane'a natural"; finalment. "confeccionar enumeracions tan completes i revisions tan generals de tot, que estigués segur de no ometre res."

L'objectiu de Descartes is aplicar aquest metode a tota la filosolia i a les altres ciències "tal com ho havia fet amb l'àlgebra". Només el mètode que garanteix les certeses matemàtiques pot resoldre satisfactòriament els dubtes sobre les certeses de la filosolia. Es tracta del conegut criteri evidencialista de la certesa, que diu que no es pot concixer cap veritat a menys que sigui immediatament evident. L'evidencia, com a únic criteri de certesa admissible, pressuposa una presentació clara i distinta. És a dir, allò evident es coneix per una intuició directa de l'esperit; la seva veritat és al mateix temps la seva junediata evidencia.

Doncs bé, nalgrat aquesta solemne declaració de principis metodològics vàlids per tota la filosofia, a continuació, en la tercera part del seu Discurs, Descartes exceptua, de les exigencies del benaurat métode cartesià, el coneixement de la moral. Impel-lit per la urgència de l'accio vital i per una aparent consciencia del caricter indissociablement prictic del dubte metòdic com a actitud, Descartes reconeix que en matèria moral resulta més raonable seguir el

\footnotetext{
I A partir doara, totes les cites del Discurs pertanyen a les dues primerts parts.
} 
que ell anomena una moral provisional abans d'endegar la tasca de conèixer una moral definitiva. En les seves paruales, "per no mantenir-me irresolut en les meves accions, pendent que la raó m'obligarà en els meus judicis, $i$ atis que no deixaré de viure tan feliç com pugui, em formaré una moral provisional, que consistirà en no més de tres o quatre màximes".

Aquesta és la proposta de Descartes; a partir d'aqui, assagem una interpretació. La remúncia de Descartes a la prioritat del coneixement moral vertader respecte de l'acció moral creiem que pot respondre a dos fets.

D'una banda, no és obvi que s'estigui renunciant al coneixement d'una moral definitiva o perfecta, sinó que provisionalment, $i$ atesa, a la vegada, la lentitud de la filosofia $i$ la urgència de l'acció, cal una guia que s'aproximi, amb les màximes garanties de certesa, a la veritat moral. Aquesta interpretació es recolça en l'advertiment que fa Descartes sobre l'estat d'espera que hem de mantenir fins que la raó ens obligarà en els nostres judicis. Altres textos també corroboren aquest fet; per exemple, quan en Els principis de la filosofia declara: "una moral imperfecta, que es pot seguir provisionalment mentre no se sàpiga cncara res de millor" (AT, IX, B, 1). Després aprofundirem més en aquest fet.

D'altra banda, però, podriem pensar que la moral, per tractar-se del terreny de la voluntat, està marcada de la racionalitat necessària perquè hi penetri cl rigor de l'esperit filosòfic. Si acceptem aquesta segona $\mathrm{i}$ agoserada tesi, estem suposant una escissió epistemològica entre raó i voluntat.

La separació entre raó i voluntat significa - breument- que les lleis de la raó no es poden aplicar a la voluntat $\mathrm{i}$ que, reciprocament, les lleis de la voluntat no estan subjectes a la raó. Aquesta és la base sobre la qual han sorgit, posteriorment a l'època moderna, part dels diferents irracionalismes. Si admetem l'escissió epistemològica entre raó $i$ voluntat, aleshores l'àmbit de la moral, construït des de $i$ per a la voluntat, es desvincula de la racionalitat $i$, en consequència, navega per un oceà d'irracionalisme. Aquest $i$ no un altrés és rumb que han adoptat els irracionalismes morals de Schopenhauer, Nietzsche, Unamuno o Camus, per posar alguns exemples.

És de tots conegut que a partir de la segona Critica de Kant, bona part de l'idealisme es va sentir més atret per la raó pràctica que per la teòrica, concedint a la voluntat un lloc de preferència, arribant fins i tot a convertir-la en el substrat últim de la realitat, com en Schopenhauer o Nietzsche. Per aquests autors, la guia de la conducta deixa de ser la raó. La voluntat assumeix la iniciativa de l'acció i fins i tot la direcció del coneixement. La racionalitat perd el seu caràcter de fundació del coneixement i esdevé una activitat derivada, a la qual només li és permés de justificar des de la racionalitat allò que, en el seu origen, és l'actuació irracional d"una voluntat no patronejada pel coneixement racional.

En aquesta linia interpretativa, dins la crítica a la racionalitat cartesiana, podem citar l'escrit Ni vitalismo ni racionalismo, d'Ortega y Gasset, ${ }^{2}$ on s'acusa Descartes d'aixecar tota la seva filosofia racional en una sorra d'irracionalitat.

Però tornem a la primera interpretació, aparentment més plausible si seguim amb fidelitat els textos. Hem de guiar-nos per una moral provisional a l'espera de conèixer una moral definitiva o, el que és el mateix, d'assolir l'objectivitat moral. Atès que la primera i més important tasca de la filosofia és conèixer les veritats evidents, també hauriem de pretendre copsar en l'enteniment les veritats morals.

2 Obras completas, Madrid: Revisla de Occideme, pp. 270-82. 
Ara bé, els éssers humans no ho podem conèixer tot, car no som Déu. En carta a Elisabeth del 15 de setembre de 1645, Descartes declara: "Perquè només Déu pot conẻixer perfectament totes les coses, és necessari que nosaltres ens contentem de saber només aquelles que es troben al nostre abast". El coneixement de la moral, pel filòsof francès, serà una d'aquestes coses que només Déu pot copsar perfectament, per la qual cosa el coneixement de les veritats morals li són negades, a l’ésser humà. ${ }^{3}$ En paraules de Rodis-Lewis, la "plus parfaite moral" equival al saber absolut, el qual només correspon a Déu, i li està mancat, a l'home. ${ }^{4}$

Per tant, atès que se'ns nega, als éssers humans, el coneixement de les veritats morals, i atès també que necessitem certeses vitals, malgrat l'absència de certeses teòriques — no es pot suspendre la determinació moral-, com Descartes fa veure en multitud de textos, ens haurem de fer amb una guia moral provisional que suplirà la incognoscible moral perfecta. En què consistirà aquesta moral provisional? En primer lloc, en el seguiment de la Paraula de Dêu, que és la forma més segura de no allunyar-nos de les veritats morals que només Díu pot coneixer. Perd, per Descartes, no n'hi ha prou en "mantenir constantment la religió en la qual Déu $m$ "ha fet la gràcia de ser instruĭt des de la meva infantesa", com ell inateix afirma. A més a més -i cito la regla primera de la moral provisional- "cal governar-se en tota altra cosa seguint les opinions més moderades $i$ les més allunyades de l'excés que a la pràctica fossin correntment acceptades pels més sensats d'entre aquells amb els quals hauria de conviure."

En aquest punt trobem la clau de la nostra interpretació. Aqui Descartes s'aparta de l'intuĩcionisme o evidencialisme metodològic que governa la seva filosolia general. En teoria moral, admet una altra aproximació metodològica per adquirir tls principis de la bona conducta. Les veritats morals no apareixen a l'individu "clares i distintes", ni poden ser derivades d'evidències "clares i distintes", sinó que cal aproximar-se a elles a través de les opinions més moderades dels prohoms més assenyats. Davant de l'absència del coneixement de la veritat moral $i$ de la presència d'un món canviant i més ric del que pot captar la lletra de la llei i de la religió, resulta mess prudent ${ }^{5}$ anar ajustant els judicis morals individuals als judicis morals madurats (els provinents dels més assenyats d'entre nosaltres), que cometre el greu error de cercar uns principis morals objectius però irreconeixibles a l'enteniment humà. ${ }^{6}$

El que resulta més interessant d'aquest fet is la contemporaneïtat de la metodologia cartesiana en teoria moral. Dins, encara, el Discurs del mètode, Descartes afirma que té la missió de "perfeccionar més i més els seus judicis i no empitjorar-los". Doncs bé, de la lectura dels textos del filòsof modern es desprén que la millor forma de perfeccionar els judicis norals, els propis i espontanis, consisteix a contrastar-los amb els judicis dels més sensats membres de la

3 El millor argument per defensar aquesta suposició ens ho proporciona Descartes en carta a lfyperaspistes, pseudònim d'un soldat de reserva anomenat Amauld, l'agost de 1641 . "En allo que afecia la conducta de la vida hauriem de desitjar tanta certesa com la que es necessita per adquirir la ciència; no obstant aixó, es demostra molt facilment que en aquella no s'ha de buscar ni esperar una certesa semblant: i per cert, es pot demostrar a priori. perqué el compost humà és per llur naturalesa corruptible, en canvi la ment és incorruptible i immortal."

4 G. Rodis-Lewis, La morale de Descartes, Paris: PUF, 1970.

5 Aqu' Roger Lefévre ( $L$ \%mmanisme de Descartes, Paris: PUF, 1957, capitol primer) creu que la moral provisional és dictada "per la raó", ja que és més prudent o racional acomodar-nos a la moral moderada dels més sensats que insistir en contixer l'incognoscible. Malgrat aixo, creiem que en aquest punt Lefevre conton la racionalitat en el sentit instrumental (mera adequació de mitjans a fins) amb el concepte de racionalitat implicit en el racionalisme cartesià: Ia raó com l'instrument que capta la veritat en forma d'evidéncia clara i distinta. Si parla de la raó en el sentit instrumental, aleshores compartim la seva tesi; peró si atribueix a la raó la capacitat de conéixer la veritat moral, aleshores no acceptem que aquesta rad dicta la moral provisional cartesiana.

6 En aquest punt, compartim ta idea de M. Gueroult (p. 255), quan afirma que "integrant el principi del millor judici possible hom renuncia a les exigències d'una moral absolutament certa." 
meva comunitat. Entre tots, jo i els més sensats, i derivat del consens, trobarem els principis morals provisionals que haurem de respectar i que ens serviran de guia en l'acció vital.

Ara no és la raó cartesiana, lidel al criteri evidencialista de certesa, la guia en la recerca filosòfica dels principis, sinó el que Descartes anomena "ie bon sense", el bon sentit. Eil bon sentit és el requeriment metodológic previ per assolir "le bon juger", el bon judici, el qual és ja l'expressió última del principi rector de l'acció moral. Per lant, el carni inetodológic que recorre la teoria moral ha abandonat la ruta que va del dubte metodic $i$ racional a la veritat clara $i$ distinta; ara el cami parteix del bon sentit per arribar al bon judici, que és el més prudent, el més assenyat.

Doncs bé, aquesta ruta és la que assenyalen els mapes de les teories morals contemporinies més productives. La trobem, per exemple, en John Rawls, ${ }^{7}$ el més important filòsof actual de la justícia, i en Jürgen Habermas i Karl Otto Apel, ${ }^{8}$ els teòrics de la moral més prolitics i influents dels nostres dies. No entrarem en la teoria moral d'Apel i Habermas per no allargar més aquesta comunicació i perquè inclou uns arguments transcendentalistes que ens allunyen del nostre objectiu. Malgrat això, a ningú, no se li escapa que cl criteri metodològic en teoria moral, que en el cas dels tedrics alemanys citats es converteix també en el criteri de certesa per l'epistemologia,' es basa en el consens, per bé que es tracta d'un consens pragmàtico-trascendental molt diferent del tipus de consens que veiem en el filòsof del segle xvil.

Més interessant resulta, per al nostre propòsit, la proposta metodològica de J. Rawls, basada en la recerca d'un equilibri molt semblant al que hem vist en Descartes.

Pel filòsof nord-america, el millor mètode per validar les nostres intuïcions o judicis morals espontanis es l'anomenat mètode de l'equilibri reflexiu ("reflective equilibrium"). L'equilibri reflexiu busca la màxima coherència entre les intuïcions morals $i$ els principis morals. La confrontació permanent entre intuïcions i principis, entesa com un procés de mutu ajustament $\mathbf{i}$ reajustament fins que s'aconsegueix una concordància parfecta entre intuïcions $\mathbf{i}$ principis, és el millor mètode per dotar-nos de bons principis èties.

Ara bé, els principis morals surten del que Rawls anomena els judicis madurats ("considered judgements"), que són els judicis emesos pels membres d'una posició o situació original. En la seva teoria moral contractualista, la posició original fa el paper de l'estat de naturalesa dels contractualistes del segle xvill (sobretot en la linia de Kant, salvant unes distàncies en les quals ara no entrem). El cas és que la justilicació dels principis ètics es producix a través d'un equilibri reflexiu entre el sentit de la justícia o sentit moral espontani i els judicis madurats dels membres de la posició original, on es donen les condicions ideals del bon judici moral.

Doncs bé, l'esquema metodològic en la teoria moral de Rawls és el mateix pràcticament que el descrit fins ara en la koria moral de Descartes. ${ }^{10}$ El sentit moral espontani en Rawls cquival al bon sentit cartesià $i$ els judicis madurats sortits de la posició original corresponen als bons judicis o les opinions dels més sensats d'entre nosaltres de què parla Descartes.

7 A Theory of Justice, Cambridge, Mass.: Harvard University Press, 1971.

8 Un text il-Justrador de la seva posició metodològica en epistemologia i en ética és K.O.Apel, Teoria de la verulad y ética del discurso, Barcelona: Paidós, 1991.

9 ibid., part 1.

10 Sense entrar obbviament $\mathrm{en}$ els continguts morals que finalment consensuen els individus que, corn molt bs recorda Descartes, "i encara que possiblement entre els perses $i$ els xinesos n'hi hagués de tan sensals corn entre nosaltres, em semblava que el més útil era regir-me segons les opinions d'aquells amb els quals hauria de conviure." És clar que es por discutir si els continguts morals defensats per Descartes són més o menys conservadors. Peró no estic comparant els continguts morals de Descartes amb els de Rawls o altetes autors contemporanis. sinó l'esquema metodológic que els porta a justificar els principis. 
En definitiva, tant si acceptem, en la teoria moral de Descartes, la separació entre raó i voluntat que donarà origen als irracionalismes dels segles xix $i \times x$ com si ens acollim a la versió d'una moral imperfecta construïda a partir de l'equilibri d'un cert consens, trobem en l'obra cartesiana una independència metodolögica de la teoria moral que es regeix pel mateix esquema que predominarà en la teoria moral contemporània; amb la qual cosa, no és gens agoserat concloure que, almeny's en els aspectes metodologics del coneixement moral, Descartes esdevé més contemporani que modem. 